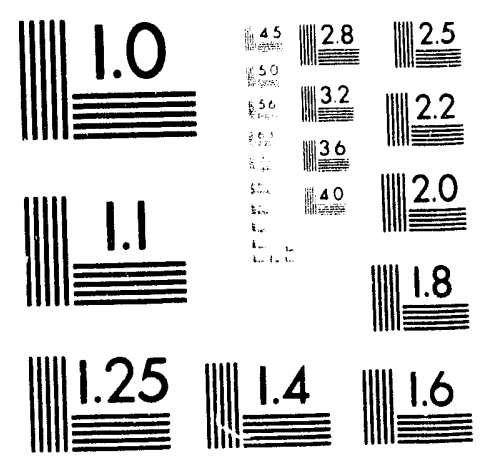



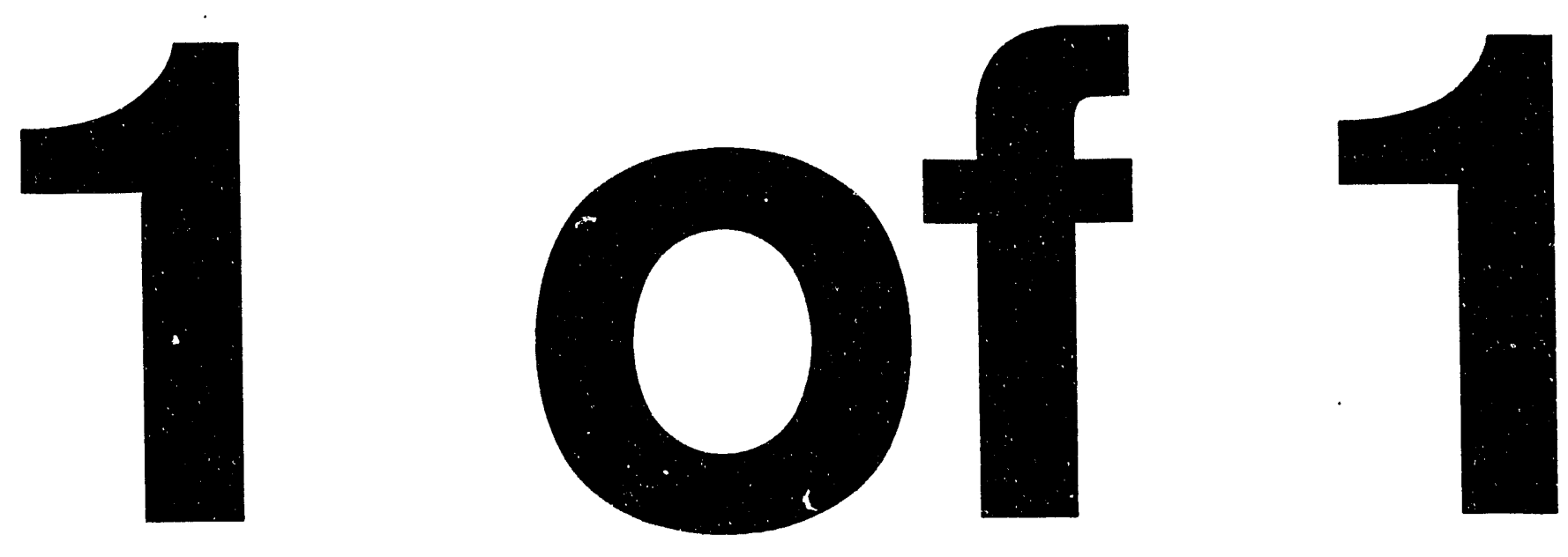


\section{The Decay of Chemical Weapons Agents Under Environmental Conditions}

Raymond R. McGuire

Jeffrey S. Haas

Rodney J. Eagle

April 9, 1993

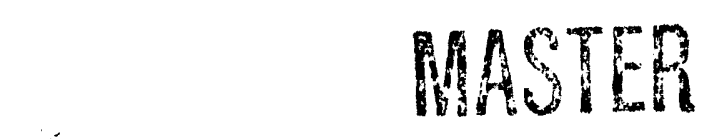




\section{Contents}

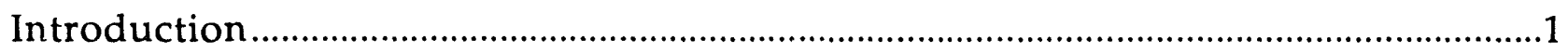

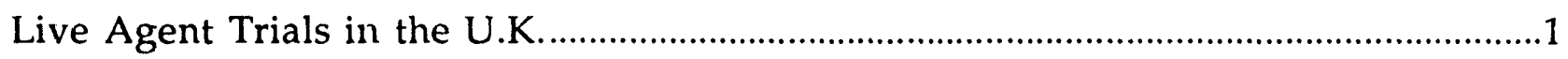

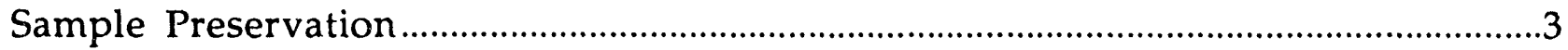

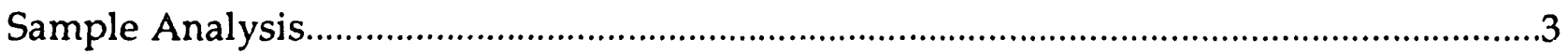

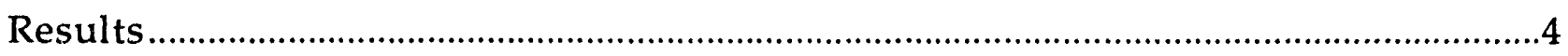

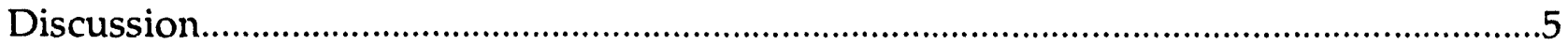

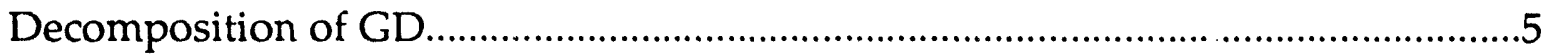

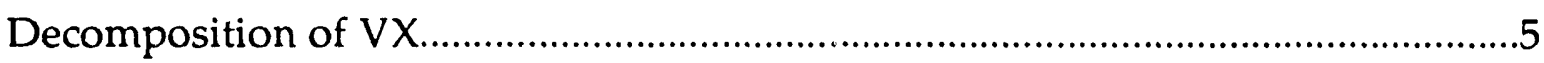

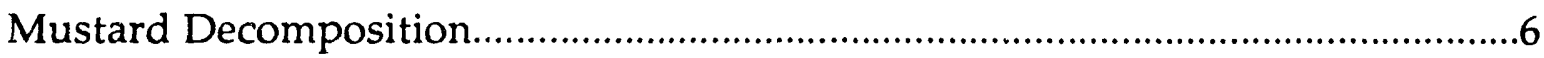

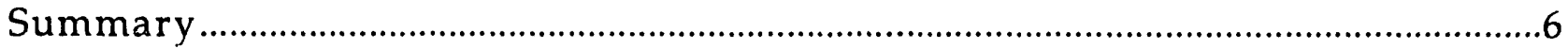




\section{The Decay of Chemical Weapons Agents Under Environmental Conditions}

\section{Introduction}

The current text of the Chemical Weapons Convention (CWC), recently signed in Paris, allows the collection of samples at inspection sites for chemical analysis. The primary aim of any analysis is to detect the presence of undeclared chemicals subject to control by the convention. In most cases the compounds of interest will be those listed on Schedule 1 in the convention text. These materials are, for the most part, known families of chemical agents. A few years ago, we at Lawrence Livermore National Laboratory (LLNL), assuming that the actual chemical agents would quickly decay under envircnmental conditions, began a study of the subsequent decay of the agent decomposition products. We further assumed that hydrolysis was the mechanism by which the agent initially decomposed in the environment. Consequently, our study focused on these hydrolysis products.

In September of 1991 we were invited by the Chemical and Biological Defence Establishment (CBDE), Porton Down, the U.K., to participate in live agent field trials they had planned. This gave us the opportunity to test our assumptions as to the rate and mechanism of decay of chemical agents in the environment.

\section{Live Agent Trials in the U.K.}

The live agent field trials began with a planning meeting on Monday, 9 September 1991. (We had received a safety briefing and been mask-fitted the previous Friday.) The plan as outlined was to deposit the agents GD (Soman), VX, and $H$ (sulfur mustard) on separate $1-\mathrm{m}^{2}$ plots on three successive days; i.e., Tuesday through Thursday. The depositions were to be made so as to give an areal concentration of $10 \mathrm{~g} / \mathrm{m}^{2}$. Four felt pads of approximately $25 \mathrm{~cm}^{2}$ each were placed at the corners of each of the test plots. These were subsequently extracted and analyzed by $\mathrm{CBDE}$ to determine the actual agent concentration. The samples for LLNL (two different types of soil, disks of silicone rubber gasket materıal, and short 
cylinders of concrete), were placed in the recesses of ceramic "spotting plates." These were, in turn, placed in petri dishes and located along one side of the area to be contaminated (see Figs. 1, 2, and 3). A related sample set, though not part of this particular study, was placed in the middle of the test area.

The Plexiglas box shown in Fig. 4 was devised by CBDE to, in theory, give a uniform distribution of agent over a $1-\mathrm{m}^{2}$ area. The agent was introduced at a metered rate onto a spinning disk at the top of the box. The falling agent droplets were then entrained in a column of air rising through perforated tubing along the sides of the box. The purpose of the air was to keep the droplets suspended for a period of time while dispersion occurs. Figure 5 shows a series of test plots laid out on the range at Porton Down.

After the agent was dispersed over the designated test plot, samples were collected immediately by CBDE personnel in protective clothing (Fig. 6), quenched in methylene chloride in specially cleaned bottles (Fig. 7), and passed across the "hot line" to the "cold" side where they were capped. The sealed bottles were imbedded in activated charcoal for transportation back to the CBDE laboratory where they were placed in a freezer at $4^{\circ} \mathrm{C}$ for storage (see Fig. 8).

Table 1 gives a chronology of the field operations. In addition to those events listed, an air-sampling experiment was performed on another part of the range on Friday, 13 September. The results of this experiment are reported in a separate CBDE document.

Table 1. Chronology of sampling at CBDE field trials.

\begin{tabular}{llll}
\hline \multicolumn{1}{c}{ Date } & \multicolumn{3}{c}{ Samples taken } \\
\hline $\begin{array}{l}\text { Tuesday, 9/10 } \\
\text { Wednesday, }\end{array}$ & GD 0-time samples & & \\
9/11 & & & \\
Thursday, 9/12 & GD 2-day samples & VX 1-day samples & HD 0-time samples \\
Friday, 9/13 & GD 3-day samples & VX 2-day samples & HD 1-day samples \\
Saturday, 9/14 & No samples taken & VX 3-day samples & HD 2-day samples \\
Sunday, 9/15 & No samples taken & No samples taken & No samples taker \\
Monday, 9/16 & No samples taken & No samples taken & No samples taken \\
Tuesday, 9/17 & No samples taken & VX 6-day samples & HD 5-day samples \\
\hline
\end{tabular}


The felt pads were analyzed to determine the actual distribution and concentration in the test area. These analyses were performed by CBDE chemists some time after the trial dates. It is clearly evident from the summaries of the results shown in Figs. 9, 10, and 11 that the agent dispersion was quite inconsistent. Only the GD dispersion was very near to the desired areal density of $10 \mathrm{~g} / \mathrm{m}^{2}$. The VX concentration was about half the desired level while that of the mustard was approximately $10 \%$.

The Livermore samples were located in the lower two quadrants of each test grid. (The approximate locations of the LLNL samples are shown by the " $x x^{\prime \prime}$ marks.)

This large difference between the planned agent concentration and what actually was delivered on the ground has caused any comparison between agents to be quite limited.

\section{Sample Preservation}

Each of the various samples was immersed in approximately $10 \mathrm{~mL}$ of dry methylene chloride. At the expected areal density of agent this would give a concentration in the parts per ten thousand range. This dilution was done for two reasons: (1) to decrease the rate of any decomposition that might occur, and (2) to reduce the hazard for transportation. After sealing, the sample containers were packed in an insulated container with dry ice and refrigerator packs.

The samples were still cold when they were received at LLNL. The individual sample containers were stored in a $4^{\circ}$ freezer until they were analyzed.

\section{Sample Analysis}

The samples were decanted and sequentially extracted with methylene chloride followed by methanol. The methylene chloride extracts were each divided into two aliquots. One portion, after the volume was reduced, was analyzed by gas chromatography / mass spectrometry (GC/MS). The second portion was taken to dryness, derivatized with "Regisil" [N,O-bis(trimethylsilyl)-trifluoroacetamide] to form trimethylsilyl (TMS) adducts and analyzed by GC/MS. The methanol extracts were all taken to dryness and treated with "Regisil" to make the trimethylsilyl 
derivatives. These were then analyzed by GC/MS. Retention times and mass spectra were compared with those of authentic standards for GD, VX, mustard, thiodiglycol, and methyl phosphonic acid. Other compounds were identified by comparison to library spectra.

\section{Results}

The following results should be viewed as only semi-quantitative. Since the homogeneity of the samples were not known, the entire sample was extracted in each case. The work-up procedures were identical, as were the injection volumes. There is at least some rationale, therefore, for comparing the ion counts as a measure of concentration even though these are not in any way quantitative measures.

The measured ion counts as a function of exposure time for GD on three substrates-Livermore soil (acidic), silicone rubber gasket material, and Oakley soil (neutral)-are given in Figs. 12,13, and 14, respectively. The ion counts as a function of exposure time for VX on silicone rubber and Oakley soil are shown in Figs. 15 and 16. We discovered that the Livermore soil and concrete had, unfortunately, not been exposed to VX when the samples were inadvertently left covered during the deposition.

We have not plotted the results of any of the samples deposited on concrete for the simple reason that no agent could be detected after the " 0 " time samples. The material was either completely decomposed by the basic substrate, or it was absorbed so tightly that it was not extractable without destroying it. In a previous study, it was determined that phosphonates were so tightly bound to concrete that hydrochloric acid was necessary to extract them.

Likewise, we have not plotted the results of the mustard analyses. The original concentrations of mustard that were deposited were so low that only trace quantities could be detected at any later times. This result was confirmed by samples of soil analyzed at CBDE, where concentrations of mustard were below detection limits.

The chemical structures of the agents tested are shown in Fig. 17. The structures of selected decomposition products detected in the analyses are given in Fig. 18. The polar decomposition products were analyzed as TMS derivatives in all cases. 


\section{Discussion}

Even though field experiments do not, in general, lend themselves to quantitative interpretation, valuable information was gained from this exercise.

In all cases the decomposition of the deposited agent was more rapid than expected. This is especially true considering that the samples were covered to protect them from gross moisture such as rainfall or dew. (They were exposed to the ambient humidity.) Had they not been so protected, we might not have been able to detect any agent after one day of exposure.

\section{Decomposition of GD}

The initial decomposition of GD results, as expected, from the hydrolysis of the P-F bond. The hydrolysis must be very rapid on all substrates as there is a fairly high concentration of phosphonate partial ester detected in the samples collected immediately after deposition. There are also somewhat smaller but still more than trace quantities of methyl phosphonic acid, the second-step decomposition product, detected in the initial samples. The concentrations of both these materials peak in the Day-1 samples and decline subsequently. Both materials are still detectable in the last samples collected, i.e., after three days. The pinacolyl alcohol was also detected as its TMS derivative, but the data was not adequate to draw any further inferences.

\section{Decomposition of VX}

The hydrolysis of VX can give rise to four products depending upon which side of the sulfur bond cleavage occurs. All four of these products, along with smaller amounts of methyl phosphonic acid, were detected in the two samples (silicone gasket and Oakley or neutral soil) that were actually exposed to VX. The decomposition of the $\mathrm{VX}$ is more rapid in the soil as seen by the rate of decrease in $V X$ and the amount of decomposition products detected. All of the decomposition products give much higher ion counts (two orders of magnitude) in the soil extracts than from the gasket material.

The results are compromised even further, however, by the presence of some unknown but significant amount of diisopropylaminoethyl chloride contamination in the initial VX. This material hydrolyzes to give diisopropylamino ethanol, 
which is also one of the hydrolysis products of VX. Both the chloride and the alcohol were detected.

\section{Mustard Decomposition}

As was stated above, the mustard was deposited in such low concentration that it could be detected only in the samples collected immediately after exposure. However, the hydrolysis product, thiodiglycol (TDG), was detected using TMS derivitization throughout the sampling time. As in the decomposition of the other agents, the concentration of TDG is highest in the samples collected after one day and decreases thereafter. The only other product identified was the six-membered heterocyclic 1,4-dithiane, which is also found in the starting mustard.

\section{Summary}

This work is best summarized by reiterating that very useful information was gained even though kinetics could not be derived. The very rapid decomposition of agents in the environment was forcefully in evidence. Decomposition products were determined and appeared to arise sequentially.

However, it is becoming very clear that the theory of using ratios of sequential decomposition products to estimate the elapsed time since the agent was deposited is probably unrealistic. Such product ratios can only be meaningful if the rates of decomposition are slow; i.e., the intermediate products are relatively stable so that concentrations can build up. The results of this experiment show that this is not the case for the decomposition of the tested agents.

It is also clear from this study that the detection of deposited organophosphate agent is unlikely in environmental samples after a few days. The initial concentration was too low for a similar definitive conclusion to be drawn for mustard. 


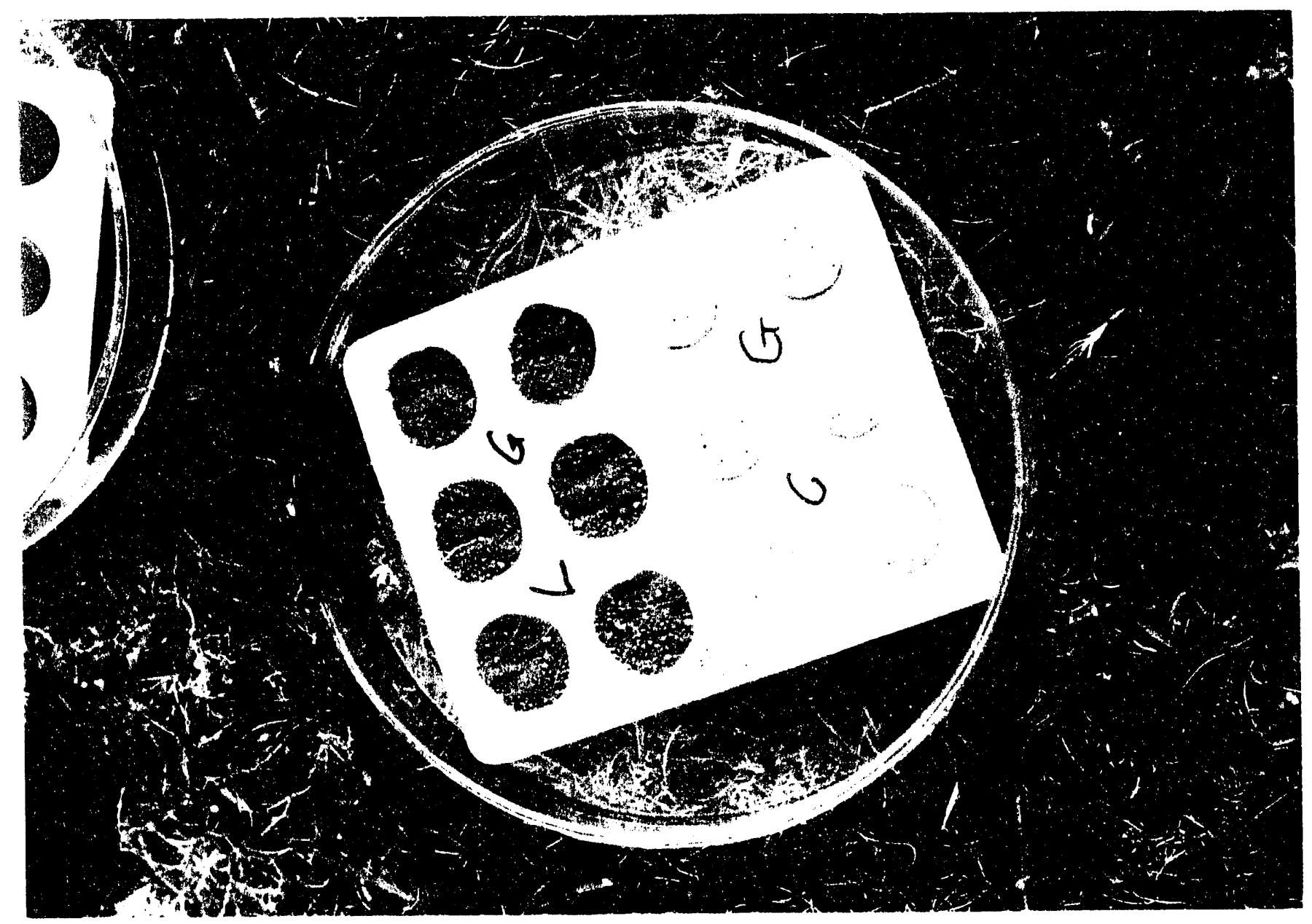

Fig. 1. Spotting plate containing Livermore soil and concrete substrates. 


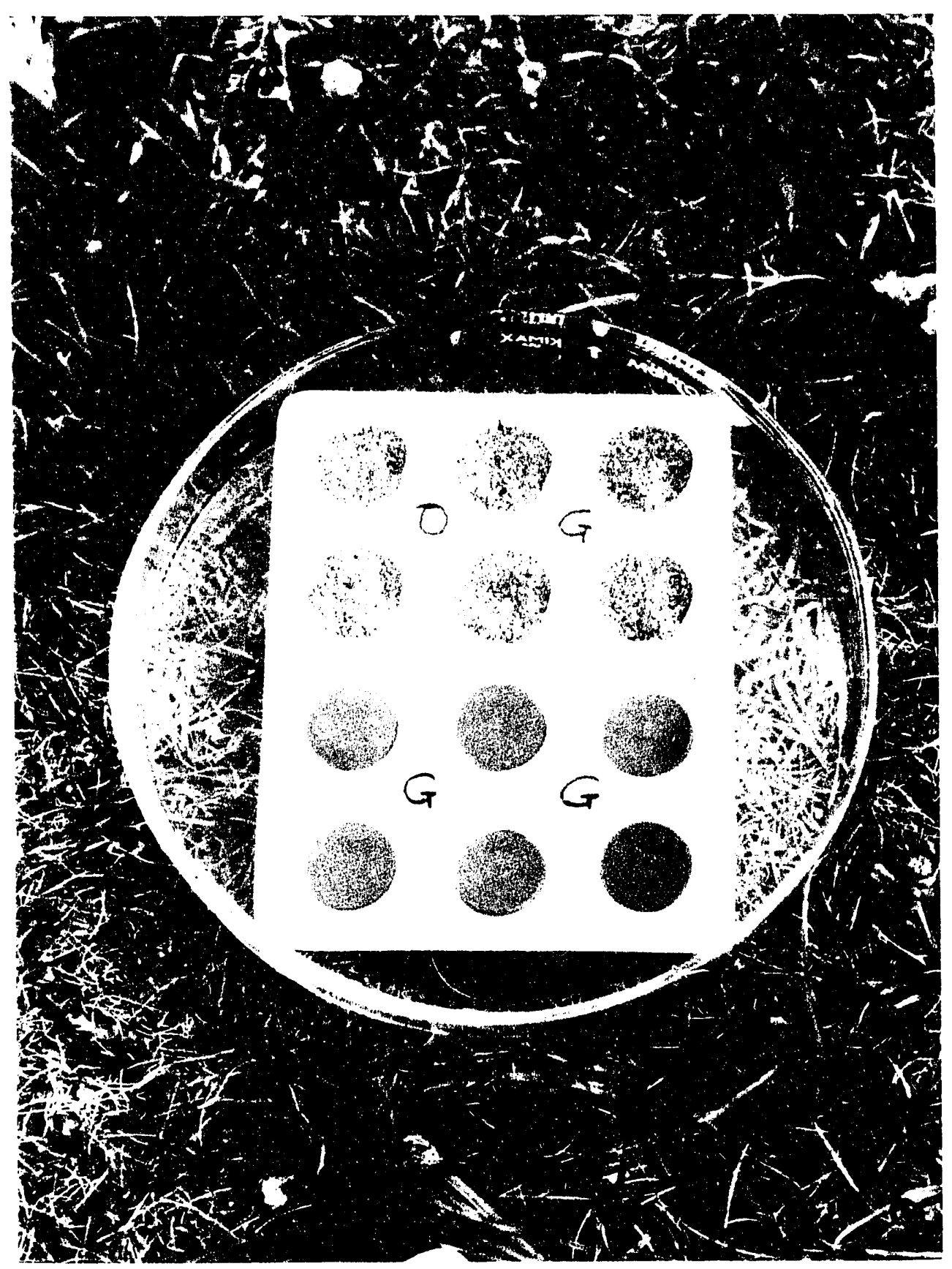

Fig. 2. Spotting plate containing Oakley soil and silicone rubber substrates. 


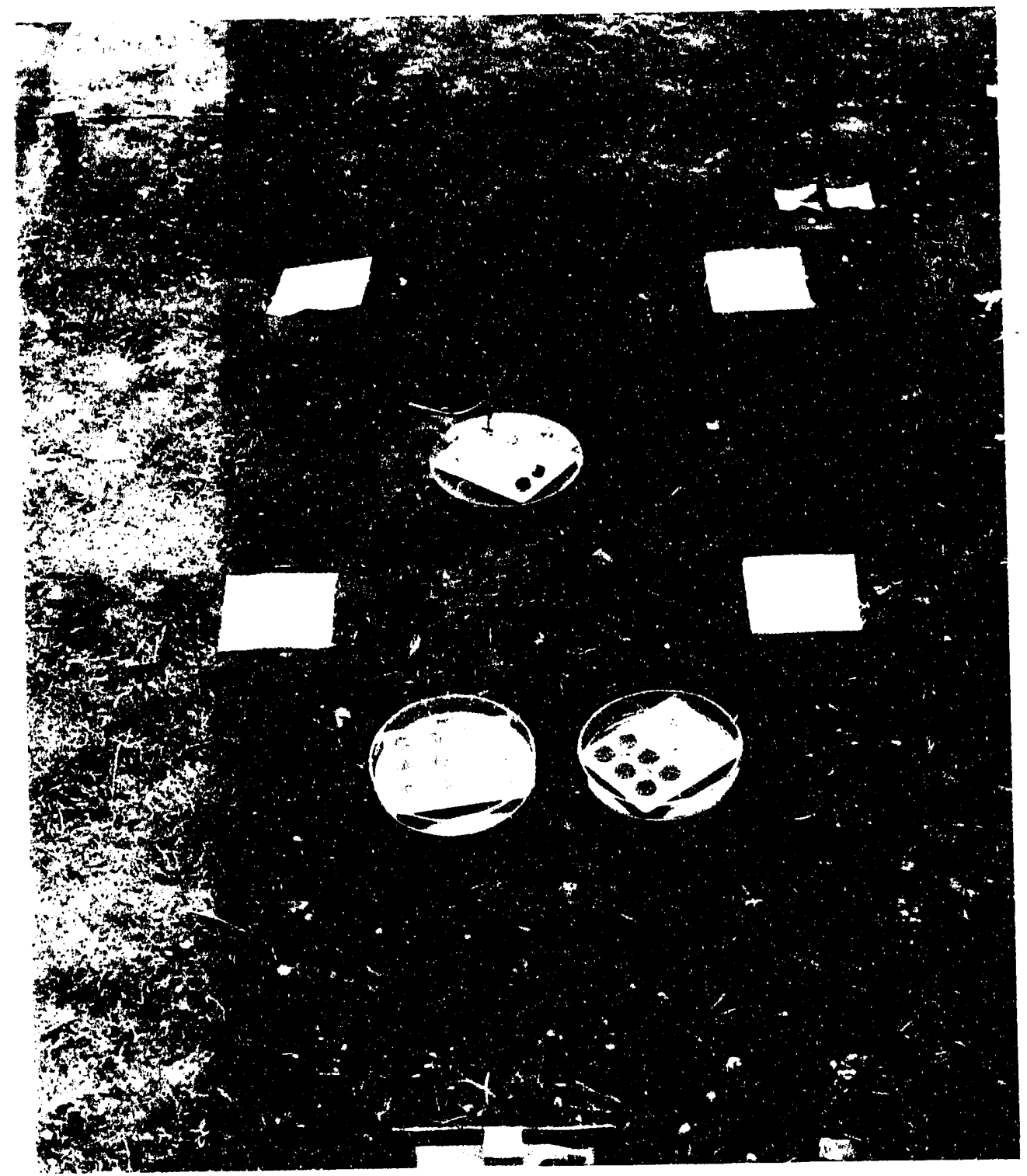

Fig. 3. Sample layout, also showing felt pads used to measure agent deposition. 


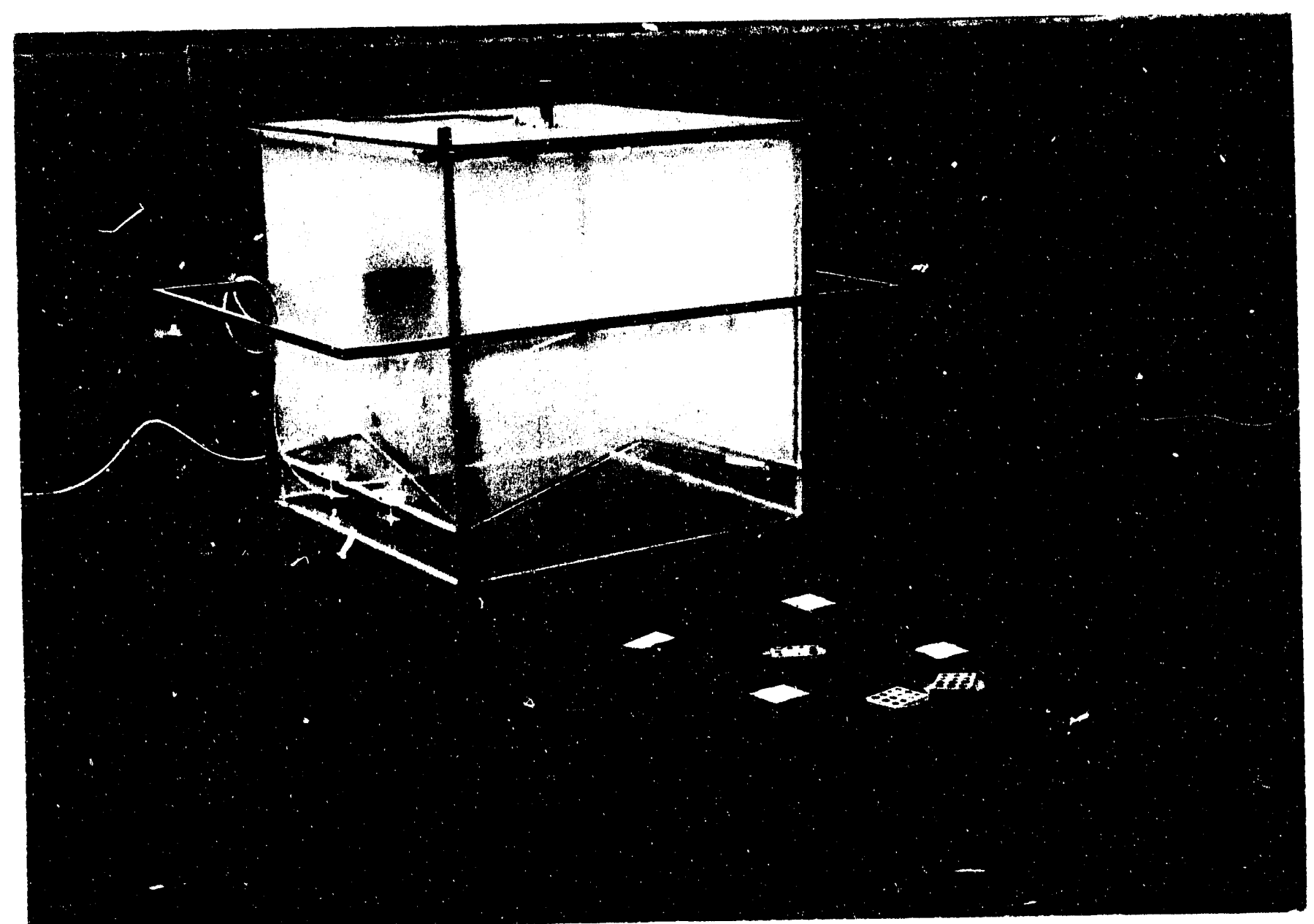

Fig. 4. Sample layout, showing agent deposition box. 


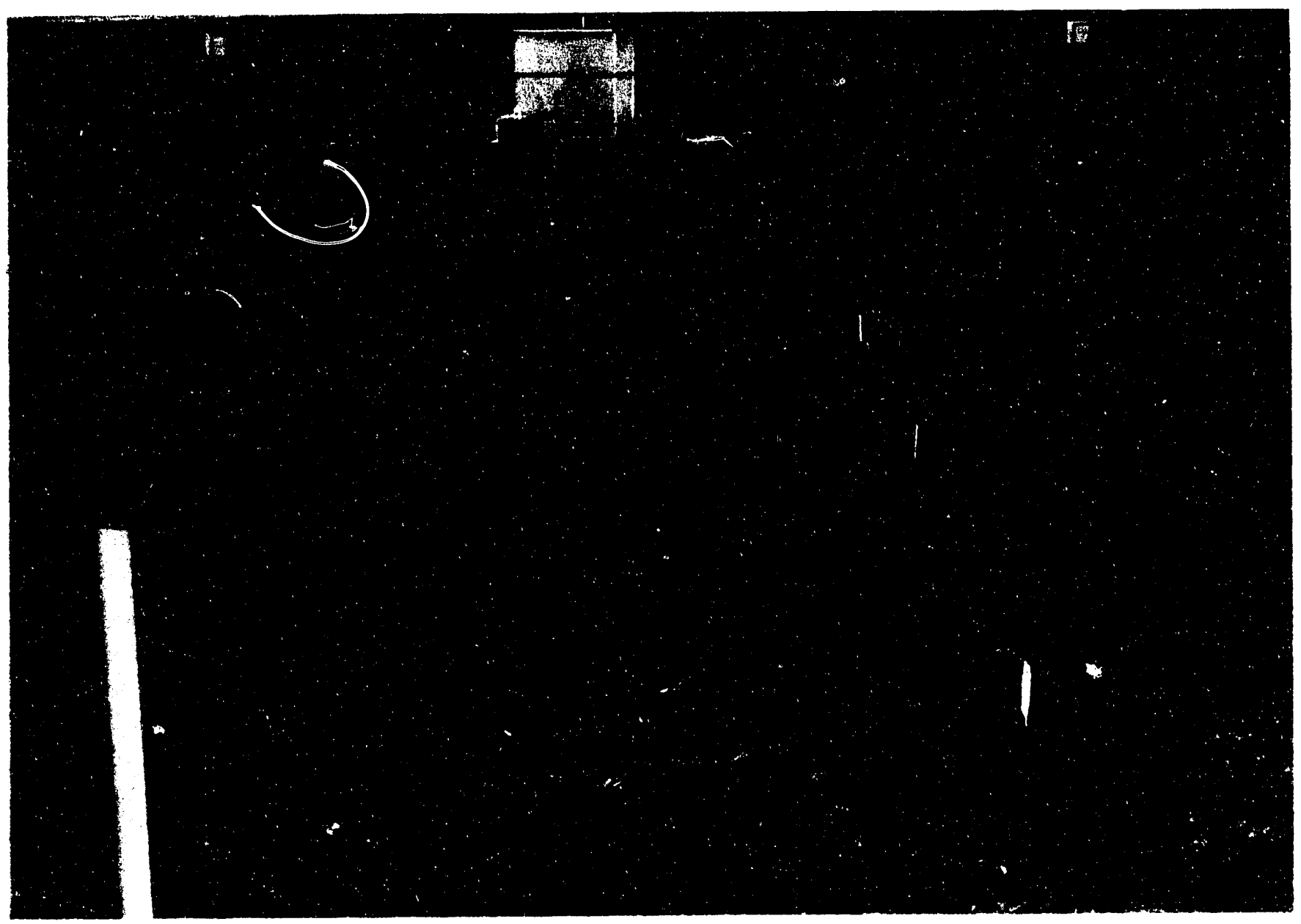

Fig. 5. Extended view of area showing test grids. 


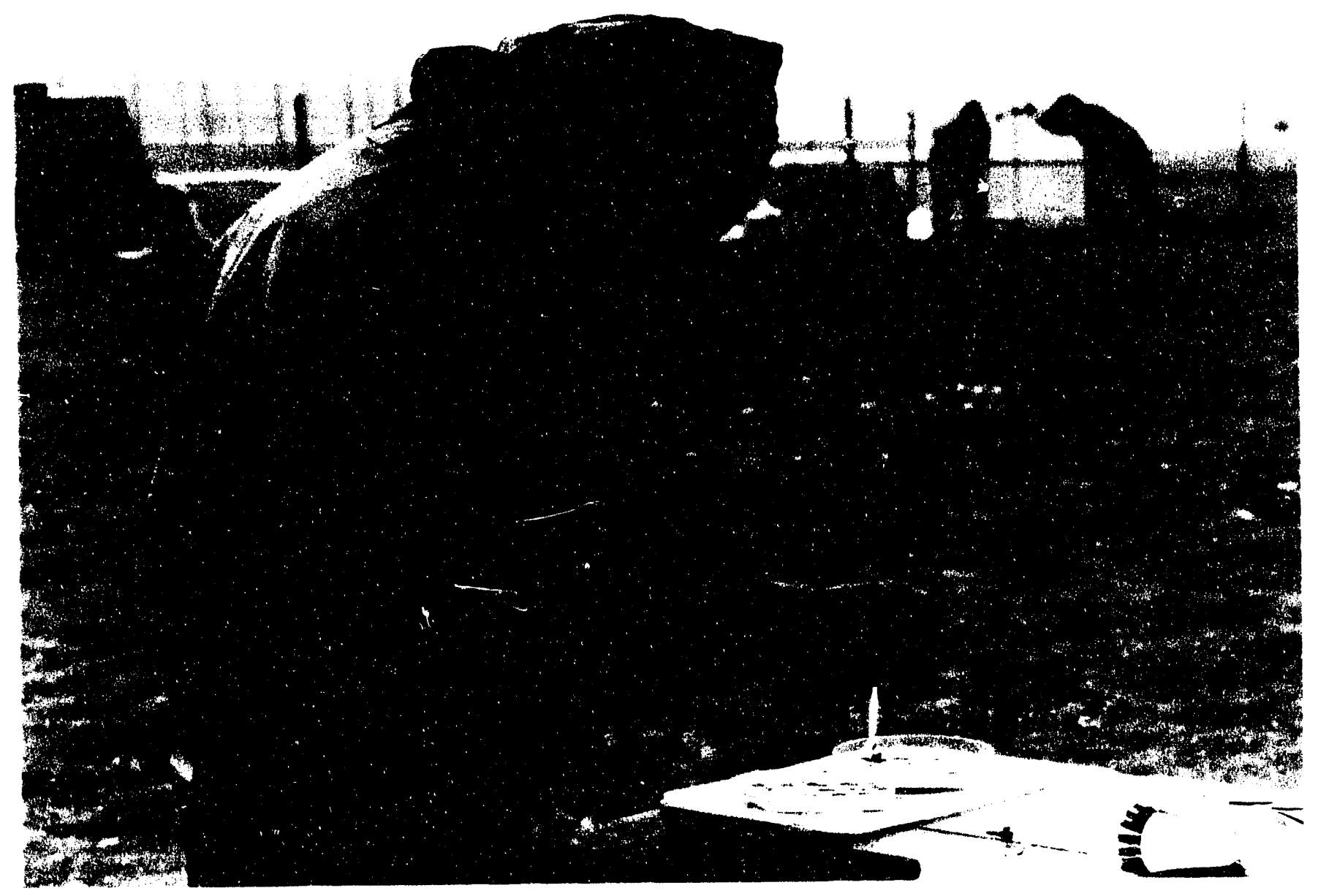

Fig. 6. Collecting one of the exposed samples. 


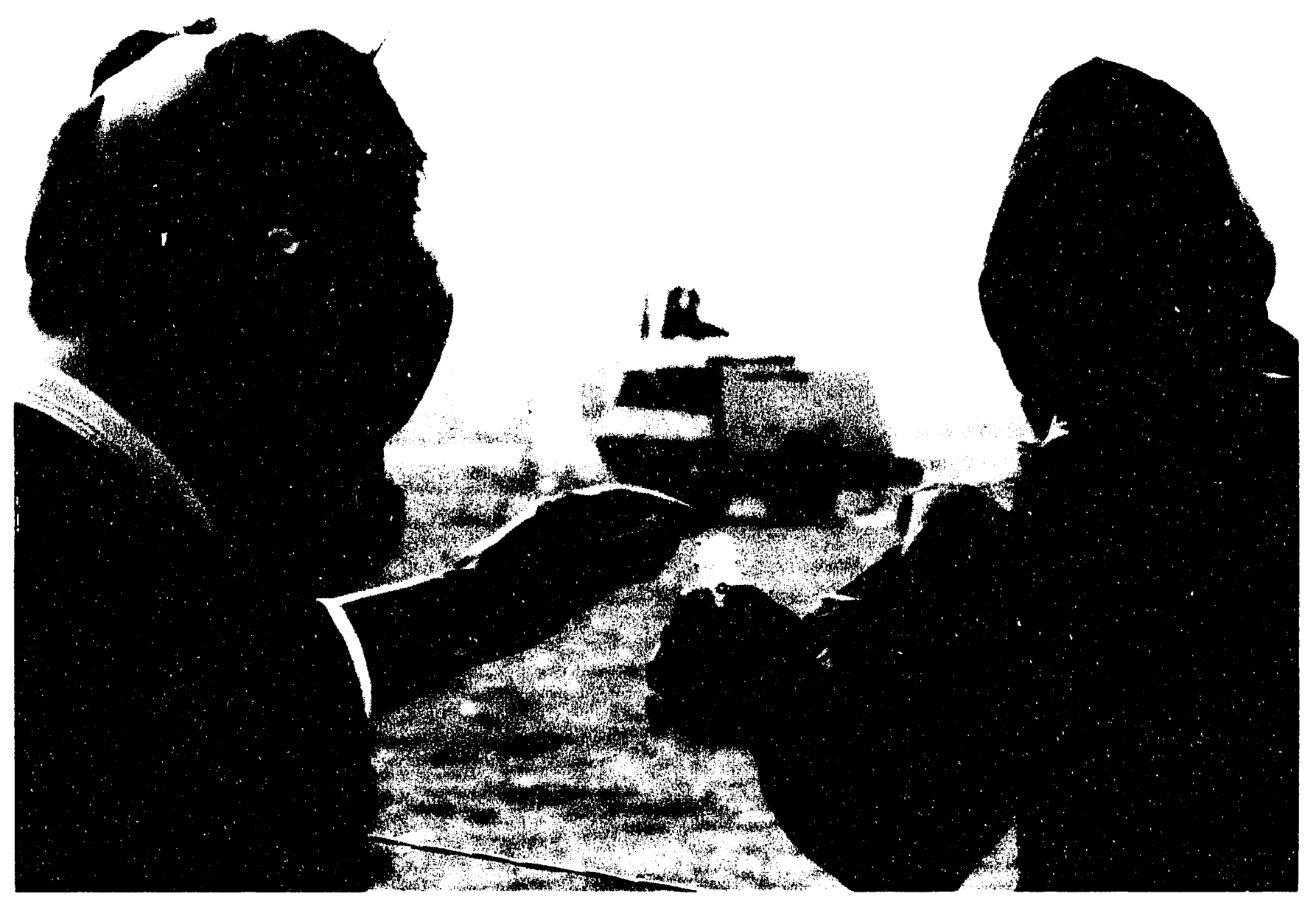

Fig. 7. Handing the collected sample across the hot line. 


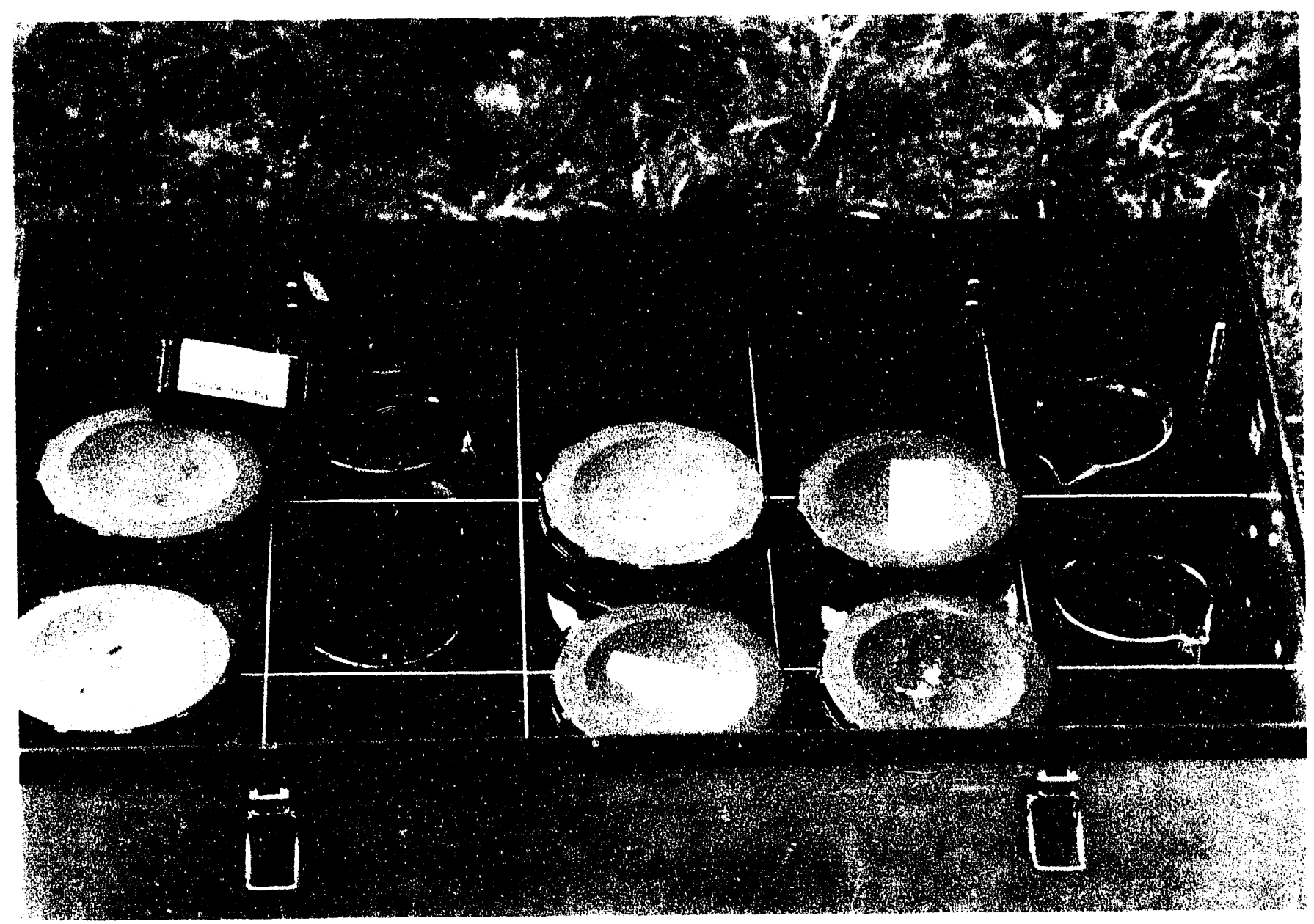

Fig. 8. Samples packed in charcoal-filled beakers for transport to laboratory. 


\begin{tabular}{|c|c|}
\hline $14.0 \mathrm{gm} / \mathrm{m}^{2}$ & $3.3 \mathrm{gm} / \mathrm{m}^{2}$ \\
\hline$x x \quad 7.3 \mathrm{gm} / \mathrm{m}^{2}$ & $7.3 \mathrm{gm} / \mathrm{m}^{2}$ \\
\hline
\end{tabular}

Average GD Areal Density $=8.0 \mathrm{gm} / \mathrm{m}^{2}$

Fig. 9. Actual GD areal concentration on contaminated area.

\begin{tabular}{|c|c|}
\hline $3.6 \mathrm{gm} / \mathrm{m}^{2}$ & $2.1 \mathrm{gm} / \mathrm{m}^{2}$ \\
\hline $\begin{array}{l}\mathrm{xx} \\
\end{array} .5 \mathrm{gm} / \mathrm{m}^{2}$ & $\begin{array}{ll}\mathrm{xx} & 3.1 \mathrm{gm} / \mathrm{m}^{2}\end{array}$ \\
\hline
\end{tabular}

Average VX Areal Density $=3.3 \mathrm{gm} / \mathrm{m}^{2}$

Fig. 10. Actual VX areal concentration on contaminated area.

\begin{tabular}{|c|c|}
\hline $1.3 \mathrm{gm} / \mathrm{m}^{2}$ & $1.9 \mathrm{gm} / \mathrm{m}^{2}$ \\
\hline $\mathrm{xx} \quad 1.2 \mathrm{gm} / \mathrm{m}^{2}$ & $0.9 \mathrm{gm} / \mathrm{m}^{2}$ \\
\hline
\end{tabular}

Average HD Areal Density $=1.3 \mathrm{gm} / \mathrm{m}^{2}$

Fig. 11. Actual HD areal concentration on contaminated area. 


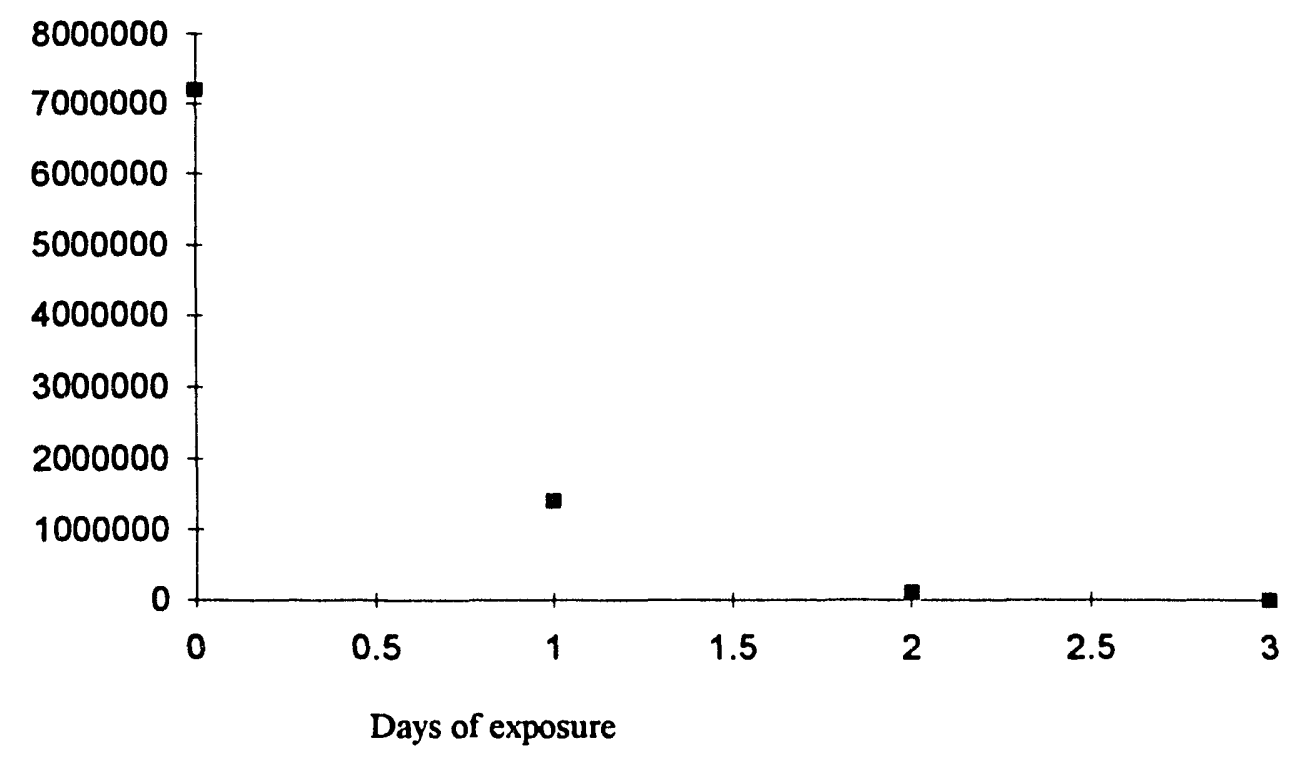

Fig. 12(a). GD ion counts as a function of exposure time on Livermore soil.

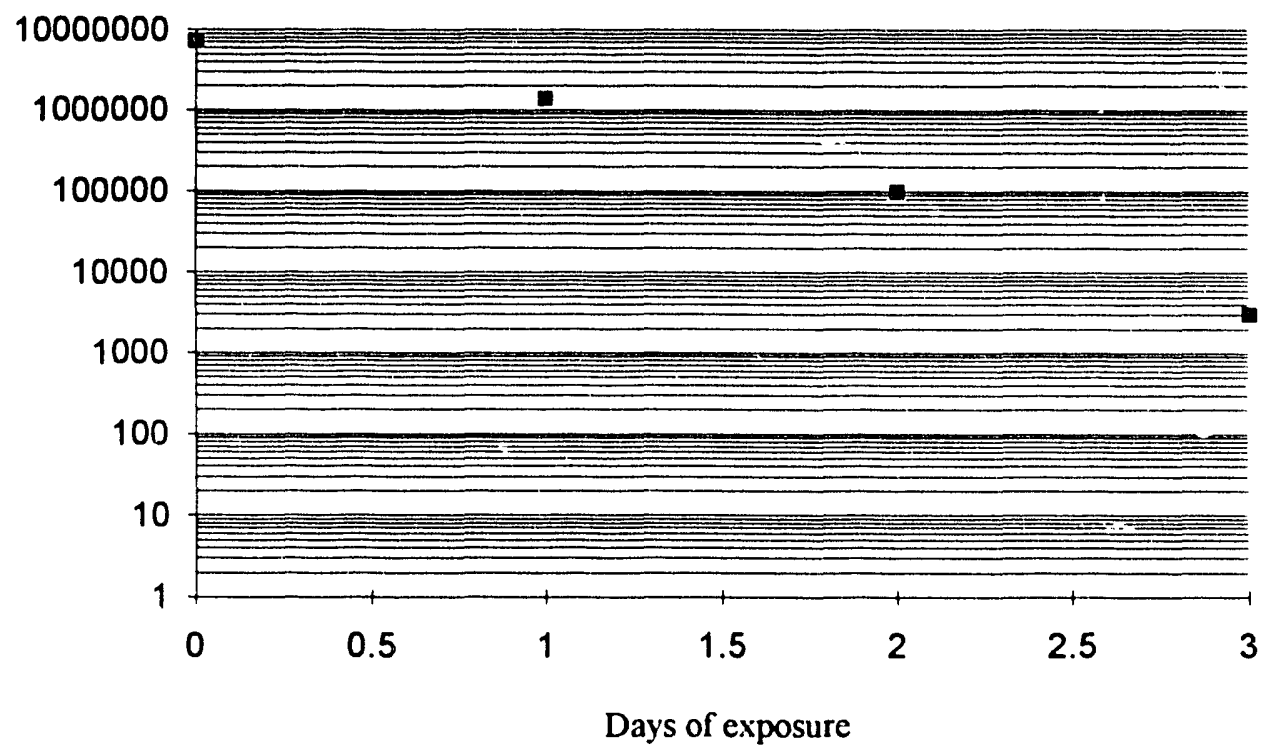

Fig. 12(b). Log plot of ion counts of GD as a function of exposure time on Livermore soil. 


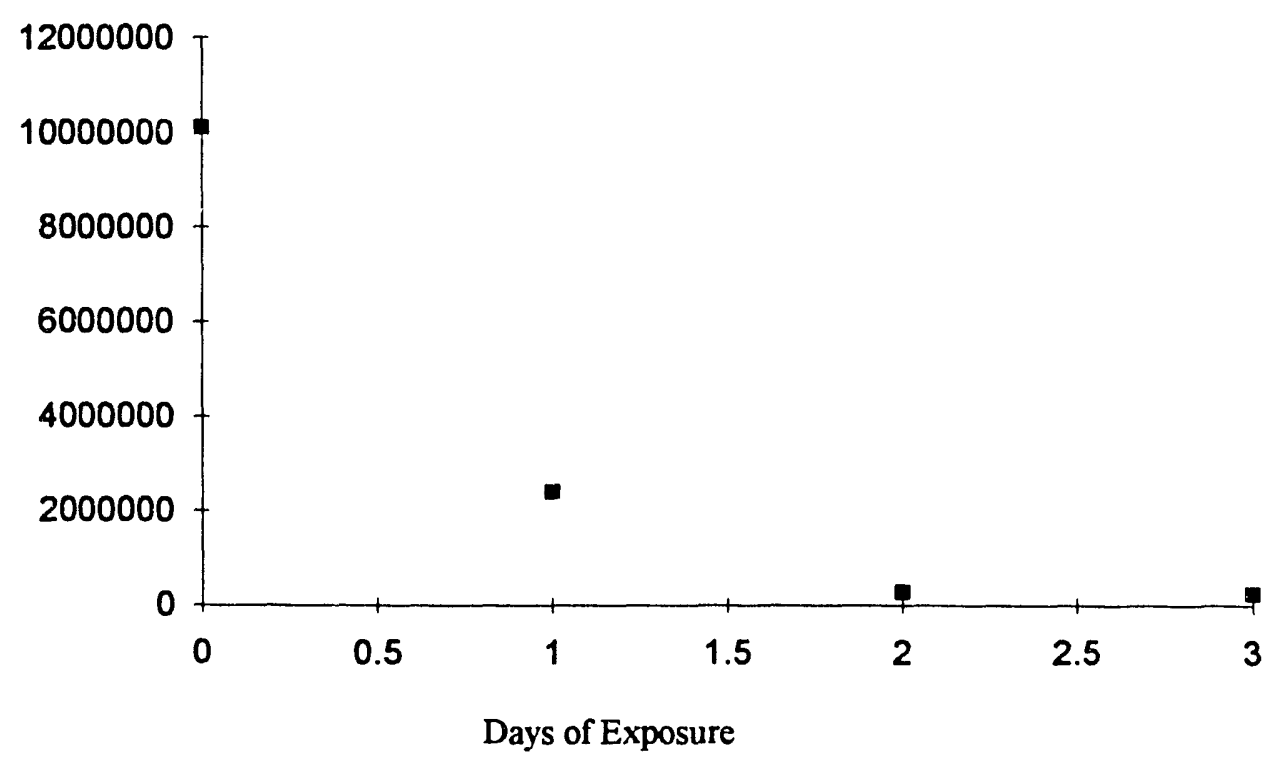

Fig. 13(a). GD ion counts as a function of exposure time on silicone rubber gasket.

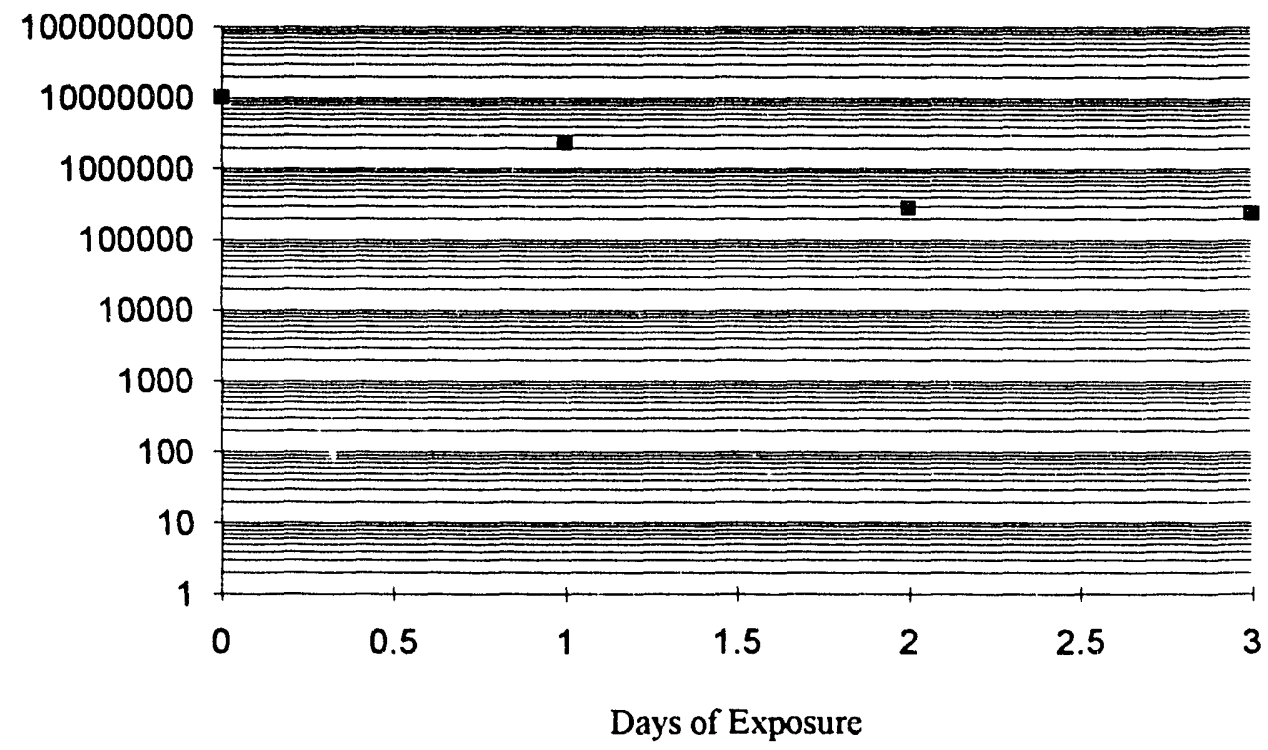

Fig. 13(b). Log plot of GD ion count as a function of exposure time on silicon rubber gasket. 


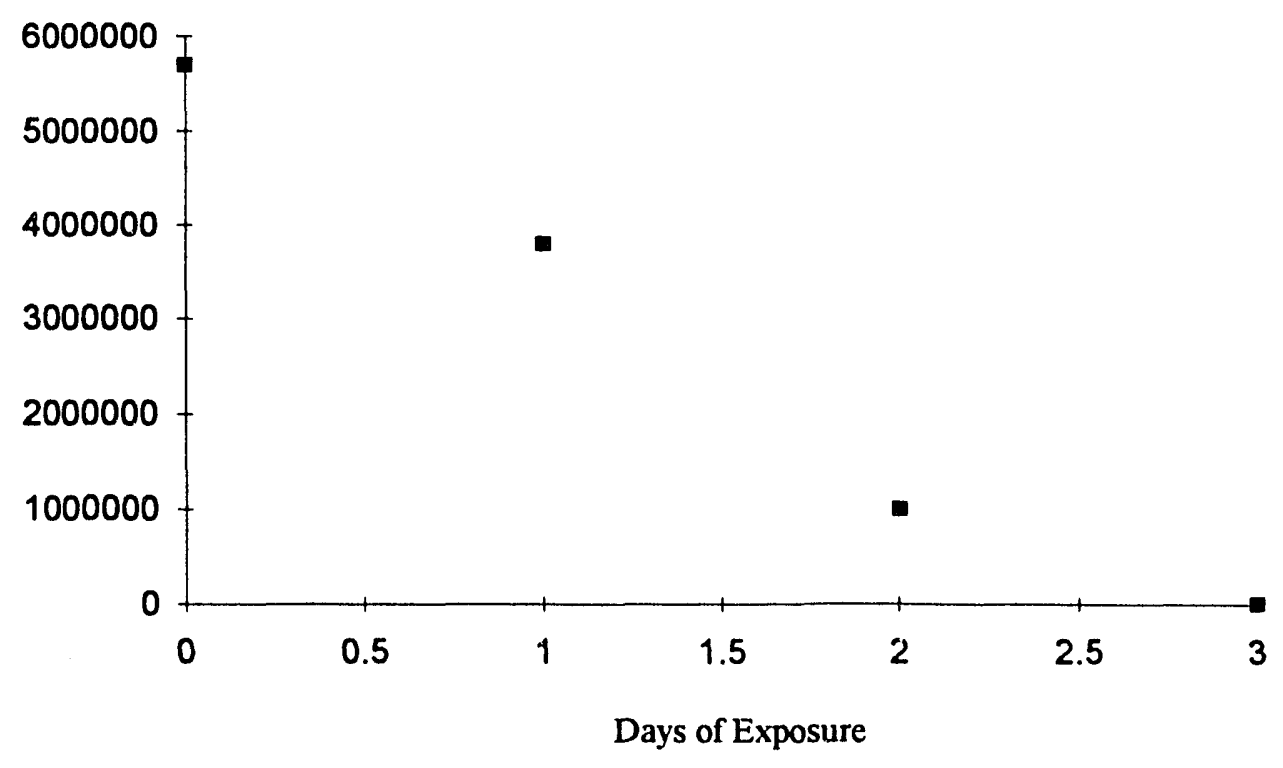

Fig. 14(a). GD ion counts as a function of exposure time on Oakley soil.

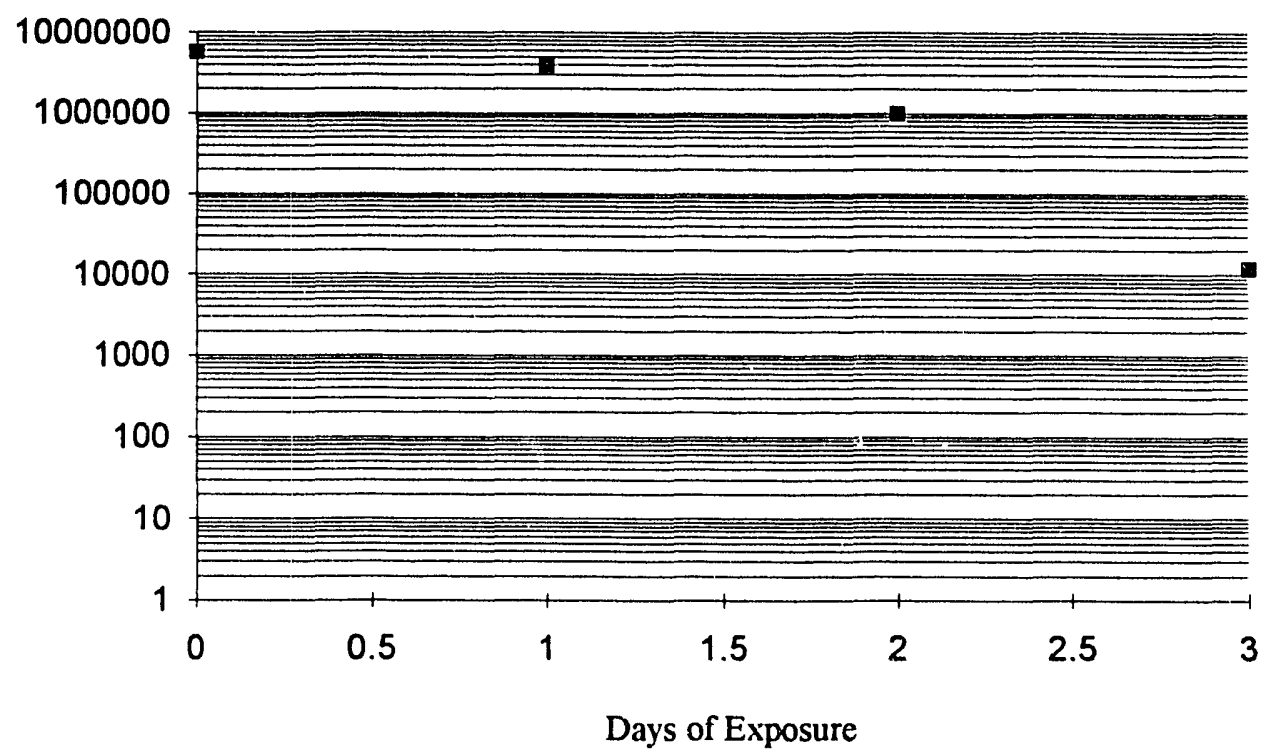

Fig. 14(b). Log plot of GD ion counts as a function of exposure on Oakley soil. 


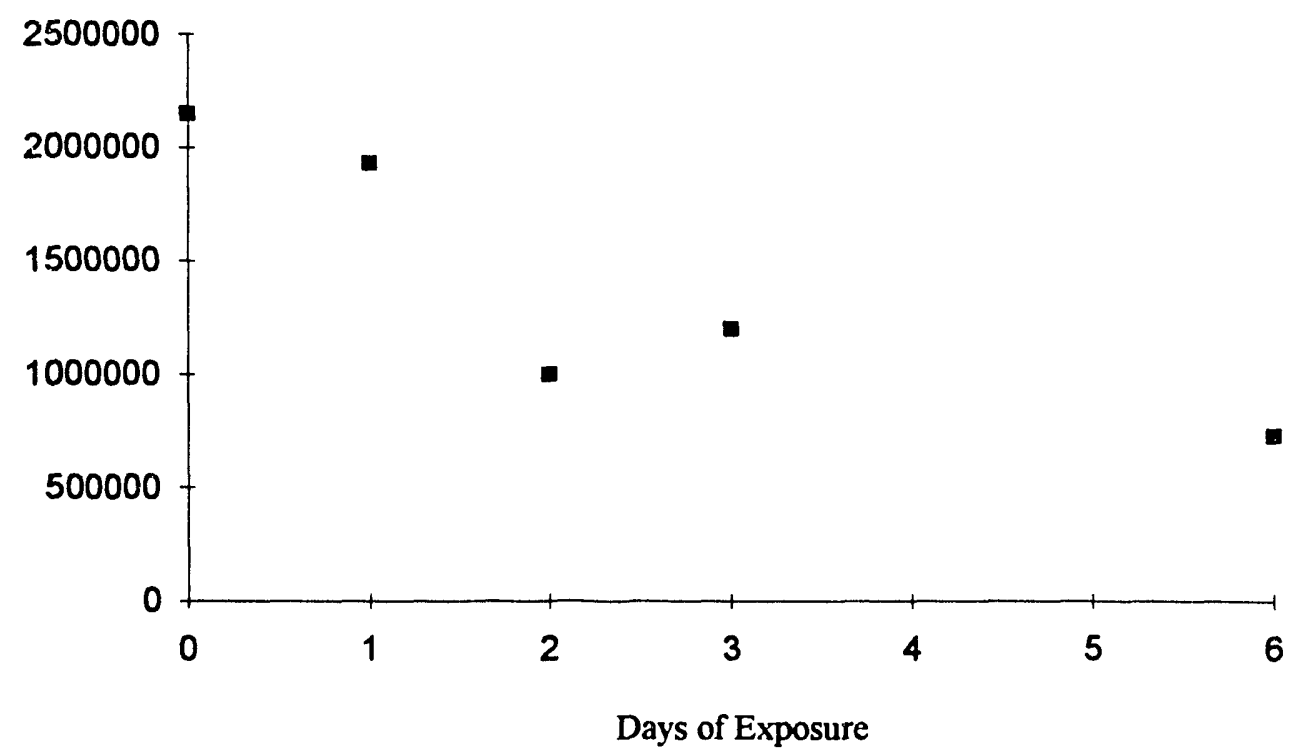

Fig. 15(a). VX ion counts as a function of exposure time on silicone rubber gasket.

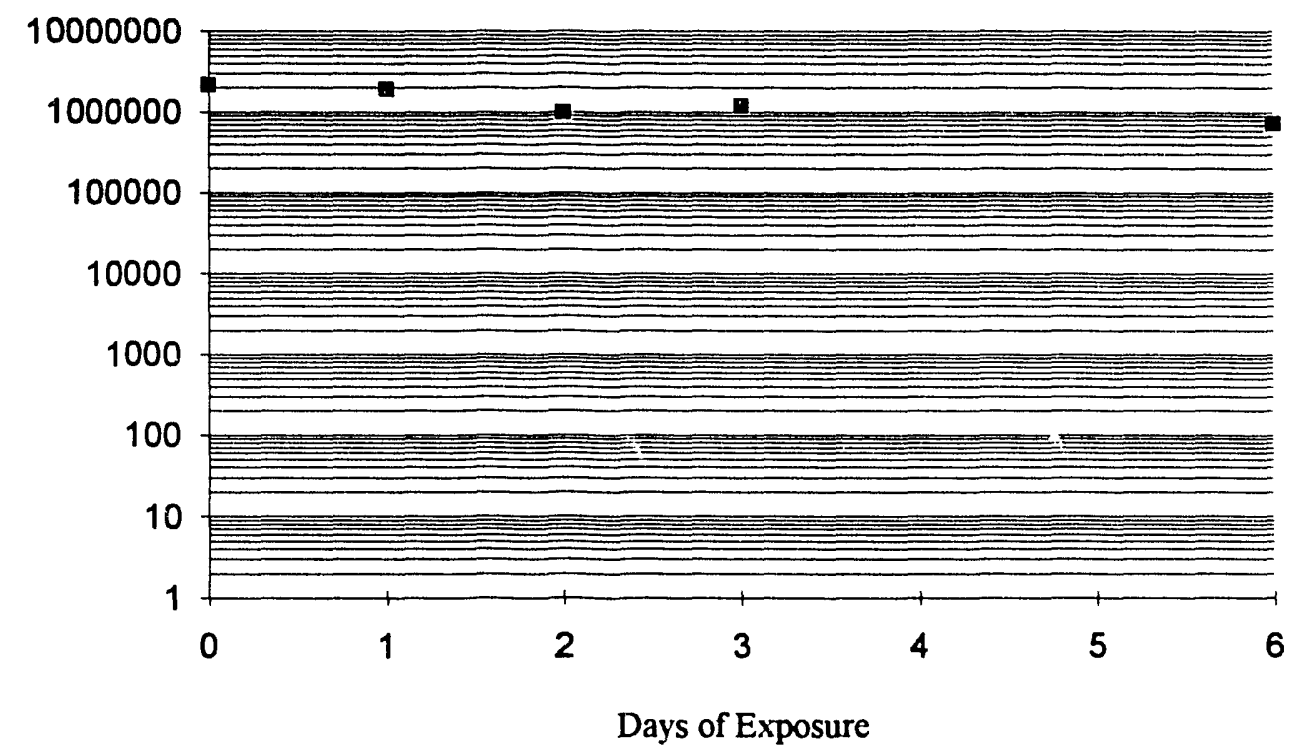

Fig. 15(b). Log plot of VX ion count as a function of exposure time on silicon rubber gasket. 


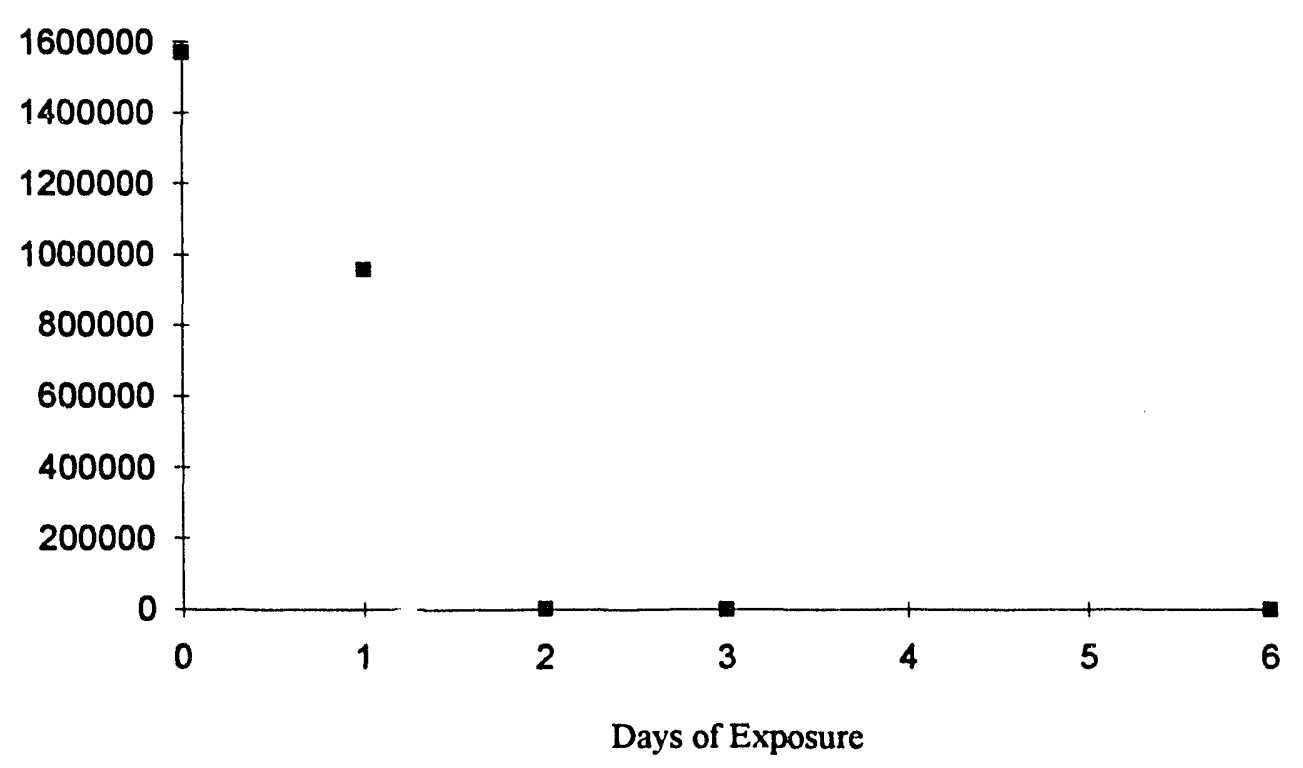

Fig. 16(a). VX ion counts as a function of exposure time on Oakley soil.

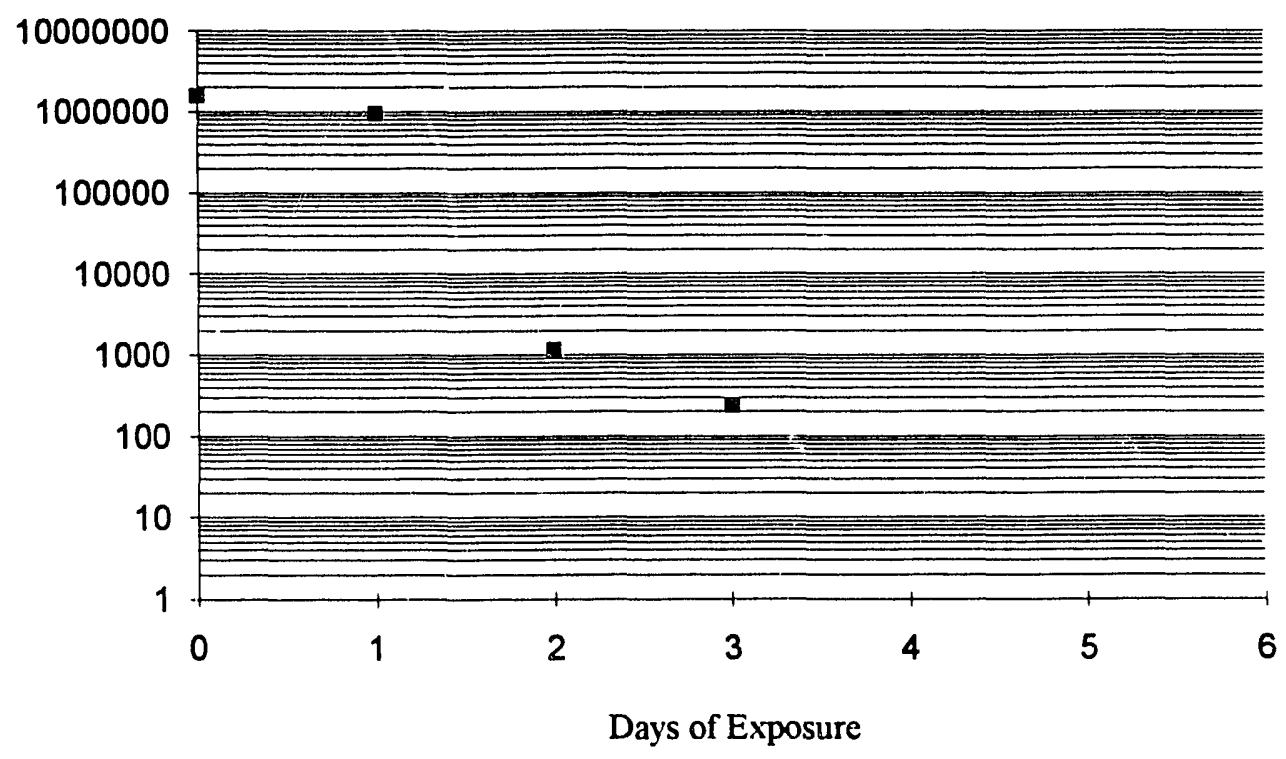

Fig. 16(b). Log plot of VX ion counts as a function of exposure on Oakley soil. 

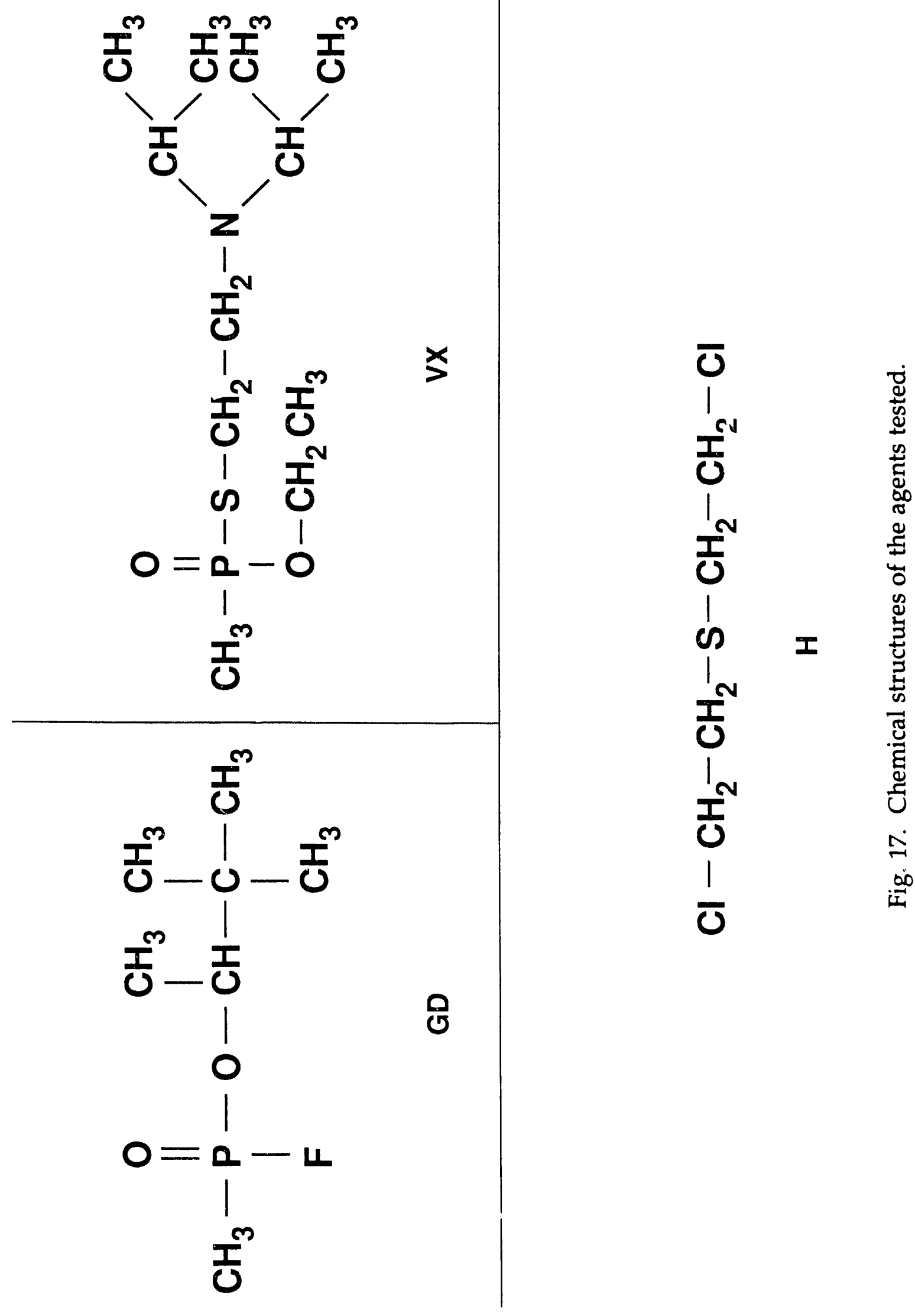


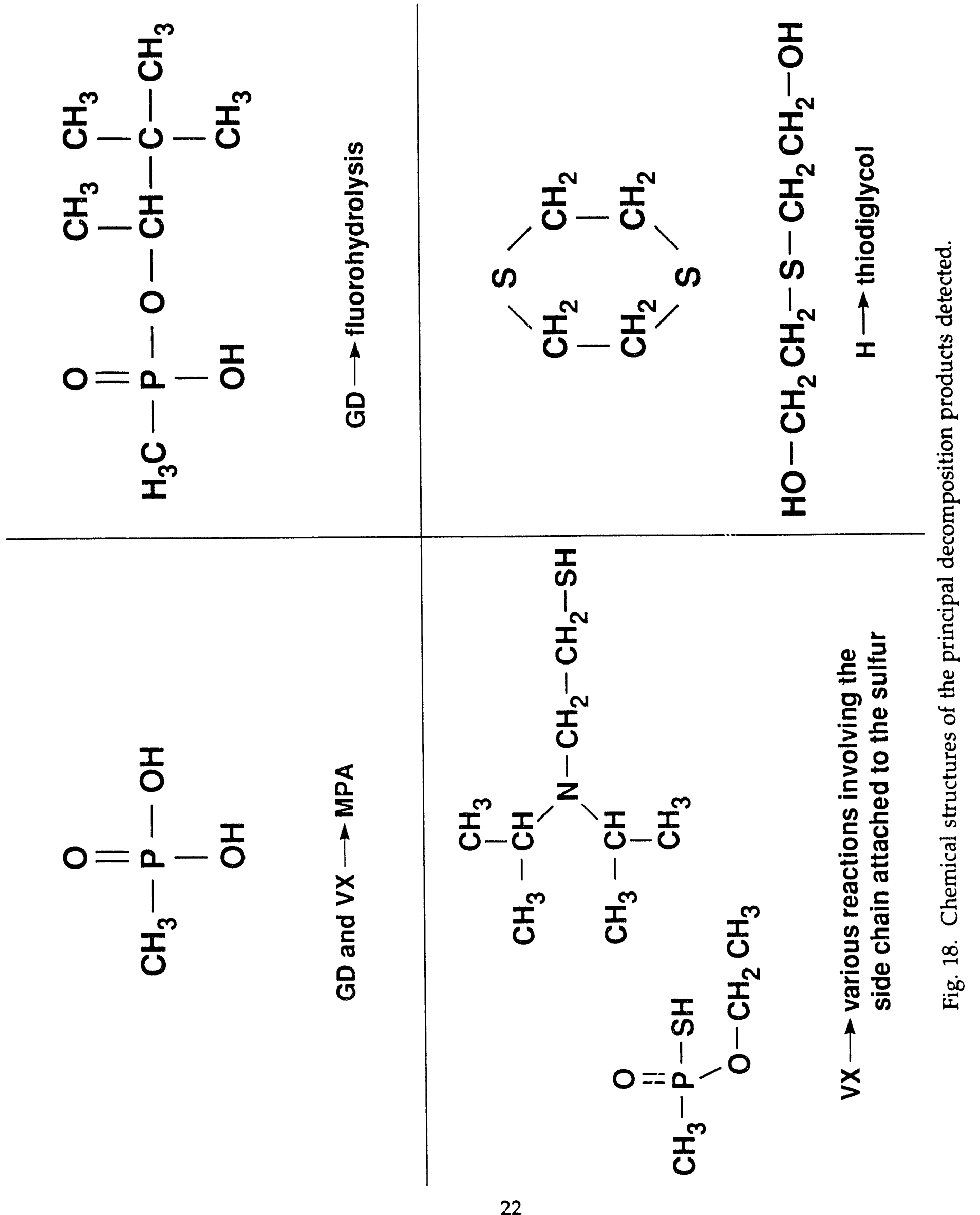



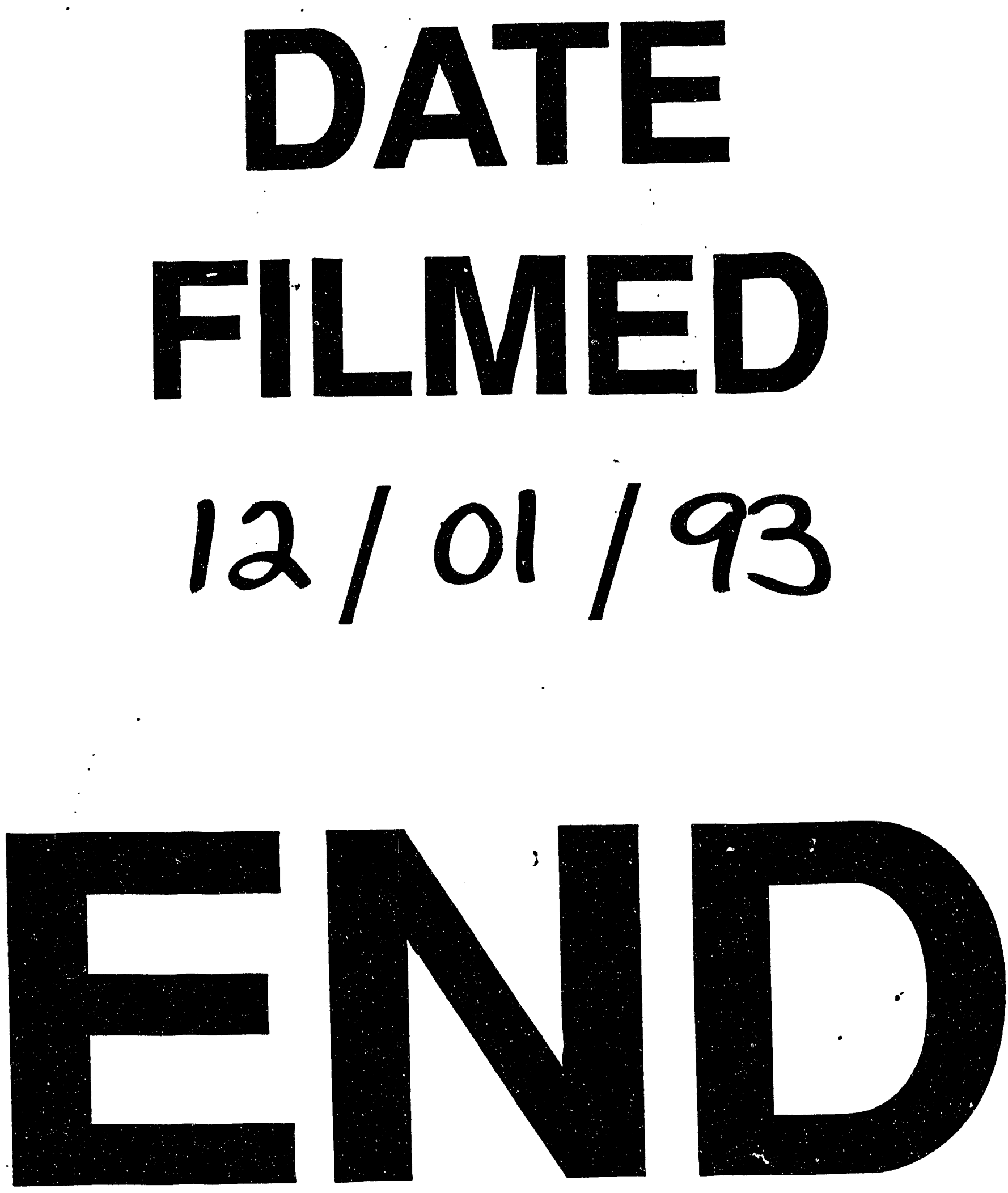